\title{
Coupling Deformation between the Non-uniform Settlement of Track-structure and Subgrade of the High- speed Railway above the Mined-out Areas
}

\author{
Shuren WANG ${ }^{I^{*}}$, Kunpeng $\mathrm{SHI}^{2}$, Youfeng $\mathrm{ZOU}^{3}$, Zhengsheng $\mathrm{ZOU}^{4}$ and \\ Adam WOJCIECHOWSKI
}

\begin{abstract}
Authors' affiliations and addresses:
${ }^{1}$ School of Civil Engineering, Henan Polytechnic

University, Jiaozuo 454003, China

e-mail: shurenwang@hpu.edu.cn

${ }^{2}$ School of Civil Engineering, Henan Polytechnic University, Jiaozuo 454003, China

e-mail: 444583054@qq.com

${ }^{3}$ School of Surveying and Land Information Engineering, Henan Polytechnic University,

Jiaozuo 454003, China

e-mail: yfzou@hpu.edu.cn

${ }^{4}$ School of Civil Engineering, Henan Polytechnic University, Jiaozuo 454003, China

e-mail: zszou@hpu.edu.cn
\end{abstract}

${ }^{5}$ Institute of Information Technology, Lodz University of Technology, Wolczanska 215, Lodz, Poland

e-mail: adam.wojciechowski@p.lodz.pl

\section{*Correspondence:}

Shuren Wang, School of Civil Engineering,

Henan Polytechnic University, Jiaozuo 454003,

China

tel.: +86 15738529570

e-mail: shurenwang@hpu.edu.cn

\section{Funding information:}

National Natural Science Foundation of China (51774112; U1810203), Fundamental Research Funds for the Universities of Henan Province, China (NSFRF200202).

\section{Acknowledgment:}

The authors would like to express their sincere gratitude to the editor and reviewers for their valuable comments, which have greatly improved this paper.

\section{How to cite this article:}

Wang, S.R., Shi, K.P., Zou, Y.F., Zou, Z.S. and Wojciechowski, A. (2021). Coupling deformation between the non-uniform settlement of trackstructure and subgrade of the high-speed railway above the mind-out areas. Acta Montanistica Slovaca, Volume 26 (4), 620-633

DOI:

https://doi.org/10.46544/AMS.v26i4.03

\begin{abstract}
China's high-speed railway has become world-famous, how to realize the safe operation of the high-speed railway passing through the mined-out areas in China will face many new challenges. To reveal the deformation and dynamic response characteristics of the track-structure and subgrade of the high-speed railway above the mined-out areas, the modeling method of transient vibration in ABAQUS was proposed, and the three-dimension computational model was built. The deformation characteristics, spatiotemporal evolution mechanism, and the law of interlayer separation under different wavelengths and amplitudes of uneven settlement of the subgrade of the high-speed railway were analyzed. The curvature radius was proposed to characterize the separation between the trackstructure and the subgrade comprehensively. Results show that the deflection of the track structure is comprehensively controlled by the wavelength and amplitude of the foundation settlement. When the wavelength is greater than $30 \mathrm{~m}$ and the amplitude is less than $0.9 \mathrm{~m}$, the deflection of the track-structure increases from fast to slow and gradually tends to be stable, and it can keep a high following with the subgrade. The separation between the track structure and the subgrade is more prominent when the radius of curvature is less than $200 \mathrm{~m}$. Otherwise, it is very weak. In addition, the dynamic response of the track structure in the separated section is more intense than that in the unseparated section. The conclusions obtained in this study can provide the reference for the construction of the high-speed railway above the mined-out areas.
\end{abstract}

\section{Keywords}

mined-out area, high-speed railway, track-structure, settlement, simulation.

(C) 2021 by the authors. Submitted for possible open access publication under the terms and conditions of the Creative Commons Attribution (CC BY) license (http://creativecommons.org/licenses/by/4.0/). 


\section{Introduction}

As we all know, China's high-speed railway has become world-famous. However, as the construction density of China's high-speed railway network increases, some high-speed railway lines have to cross the mined-out areas. For example, the Hunan high-speed railway from Hohhot to Nanning, with a design speed of 250-350 km/h, passed through the mined-out areas of the Qinshui Coalfield in Shanxi Province, China. High-speed railway passing through the damaged ground in the mined-out areas and the repeated vibration on the subgrade and track-structure, which can cause excessive additional settlement and may lead to instability and damage of the subgrade and trackstructure in severe cases. Therefore, under the action of the high-speed railway, it is a challenging problem to research the deformation and dynamic response characteristics of the foundation-subgrade-track structure for China's high-speed railway (Ren et al., 2020; Wang et al., 2015).

When the high-speed railway crosses the damaged foundation in the mined-out areas, under the repeated dynamic load of the high-speed railway, the additional stress generated by the foundation may break the stress equilibrium state of the overburden rock and reactivate in the mined-out areas, resulting in the additional movement and cumulative deformation of the foundation will result in an uneven settlement, partial tilting, and catastrophic damage to the high-speed railway until the overlying rock collapses in the mined-out areas, which seriously affects the planning and construction of the high-speed railway above the mined-out areas, also poses serious potential risks of the operation, maintenance, and repair of the high-speed railway. How to realize the safe and stable operation of the high-speed railway passing through the mined-out areas in China will face new challenges.

Therefore, it is of great theoretical significance and practical value to study the deformation and dynamic response characteristics of the track structure and subgrade caused by the settlement of the foundation above the mined-out areas. In addition, the deformation characteristics of the track structure caused by the uneven settlement of the subgrade can be used for safety assessment and design optimization of the construction of the high-speed railway above the mined-out areas.

\section{State of the art}

Due to the difficulty and low feasibility of the field test of the high-speed railway above the mined-out areas and the complex operation of the indoor model test, it is difficult to control the amount and range of the settlement in the mined-out areas, so it is impossible to systematically study the deformation characteristics and evolution mechanism of the track-structure and subgrade of the high-speed railway above the mined-out areas. While the numerical simulation method reflects its unique value (Lee et al., 2017; Krantovska et al., 2019). The finite element method can not only reflect the geometric and stress conditions of the foundation-subgrade-track structure (FST) but also consider many factors that are difficult by using the analytical method (Guo et al., 2018; Billenstein et al., 2018). Neves and Peixer et al. (2021) used a three-dimension (3D) model to solve the local deformation of the slab accurately and evaluated the operation safety of the high-speed railway on the continuous viaduct with different track conditions (Guo et al., 2018). Salcher and Adam (2015) proposed a substructure method considering the influence of the track irregularity by analyzing the dynamic response of the trains passing through railway bridges; they proved the importance of considering the track irregularity for reliable prediction of the acceleration response (Solonenko 2019; Salcher et al., 2020).

Recently, many studies have been carried out on the safety of the track structure and subgrade of the highspeed railway. The research mainly focused on the evolution mechanism of the cumulative deformation of the track-structure and subgrade under the vibration load, the impact on the mechanical characteristics, the dynamic response and driving safety of the track structure (Huang et al., 2017; Yi et al., 2019; Zhang et al., 2020). However, there is little research on the special geological type of the high-speed railway crossing the mined-out areas. Using frequency response function and peak vibration acceleration as the evaluation indicators, Yang et al. (2019) analyzed the dynamic response of the tunnel structure under the single-point vibration loads with train speeds of 300 and $350 \mathrm{~km} / \mathrm{h}$, respectively. Based on the multi-scale and refined modeling technology, Xue (2017) and Wang et al. (2019) summarized the distribution characteristics of the vibration acceleration of each part of the FST in time and space, and they verified the advantages of the solid unit in simulating the spatial vibration response of the track. To study the effect of the long-term dynamic load on the cumulative deformation of the tunnel lining under HST, Yi and Wang et al. (2019) carried out a 1/10 scale model test and numerical simulation, revealing the effect of the long-term dynamic load of HST on the cumulative deformation of the underground tunnel structure. Mezeh et al. (2021) proposed a 3D fully coupled model to simulate the dynamic behavior of the railway tracks under real excitation. Ntotsios and Colaco et al. (2021) proposed the experimental characterization of the structures near the railway and developed a way of dealing with the interaction between the soil and structure along the railway. Bian et al. (2021) studied the mechanical properties and durability of the railway subgrade by the laboratory tests; they found that the polyurethane grouting technology could effectively restore the uneven settlement of the track and provide sufficient long-term durability under the moving train load. 
Although many scholars focused on the settlement of the buildings (structures) above the mined-out areas, there are few reports on the deformation and dynamic response of track-structure and subgrade of the high-speed railway passing through the mined-out areas. Ren et al. (2018) analyzed the settlement and deformation of the building foundation above the mined-out areas and evaluated the suitability of the foundation of the mined-out areas. Wang et al. (2009) built a 3D calculation model based on MIDAS/GTS program and established the prediction method of the ground subsidence of the highway tunnel above the mined-out areas, and they predicted the key parts of the deformation and stress of the tunnel lining and bridge piers. However, the influence of the residual deformation of the mined-out areas on the above high-speed railway has not been further studied (Zhang et al., 2011).

Due to the previous studies rarely considered the interaction among the foundation-subgrade-track system, based on the engineering background of Taijiao high-speed railway passing through the Qinshui mined-out areas in Shanxi Province, China, an advanced ABAQUS/CAE method was introduced to model the transient vibration of the FST system. The proposed method can not only determine the deflection of the track structure and subgrade but also estimate the void and resonance amplitude between the track structure and subgrade. The main factors that affected the resonant amplitude values or the performance of the track structure were analyzed. Results show that compared with the mathematical modeling alone, the 3D finite element modeling of the track structure and subgrade of the high-speed railway can observe its behavior faster and more effectively.

The rest of this study is organized as follows. The relevant background and research methods are described in the Materials and Methods section. Then the results and discussion are given, and finally, the conclusions are summarized.

\section{Materials and Methods}

\section{Engineering Background}

The section DK259+135.95-DK259+710.00 in the mined-out areas of Taijiao high-speed railway was located in Jincheng, Shanxi Province, China. The region was divided into plain, hilly, and mountainous terrain, with a total area of $9490 \mathrm{~km}^{2}$, of which the mountainous area accounts for $58.6 \%$, hilly area $28.5 \%$, and plain area $12.9 \%$. There were main gully landform, gully development, and topographic relief. The average altitude of Jincheng city was 600-700 m, of which Shunwangping was the highest point in Zhongtiao mountain, up to $2322 \mathrm{~m}$, and the lowest point was located in the valley of Danhe and Qinhe rivers, with an altitude of $300 \mathrm{~m}$. The line DK259+135.95 to DK259+710.00 was mainly mined-out areas. According to the exploration data, the strata could be roughly divided into sediments, mudstone, limestone, and sandstone, from top to bottom of the mined-out areas. There was no fault in the whole area. The geological section is shown in Fig. 1. According to the different spatial positions of the mined-out areas and the high-speed railway line, the mined-out areas are divided into No. 1 to 4 , and the spatial position relationship is shown in Fig. 2.

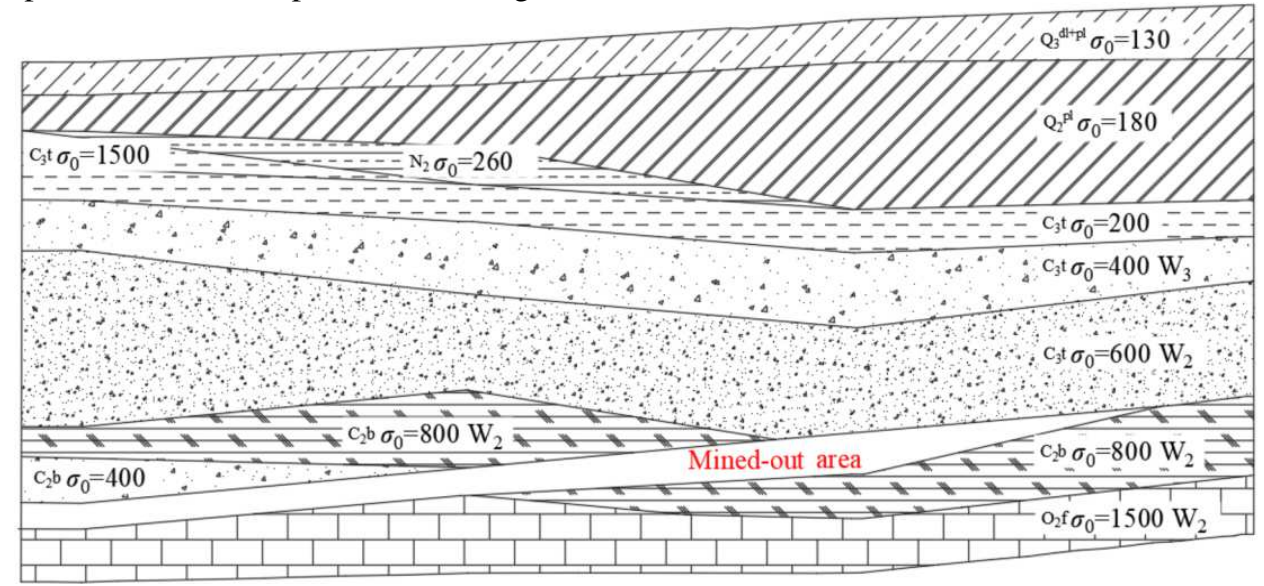

Fig. 1. Geological profile of the mined-out areas (Horizontal 1:200, vertical 1:500)

\section{Numerical Calculation Analysis}

Modeling of the Foundation-subgrade-track Structure. As the residual deformation of the foundation above the mined-out areas is a long-term evolution process, the foundation under the action of the high-speed railway is bound to cause varying degrees of damage to the subgrade-track structure and affect the safety of the train operation. To study the coupling effect of the geometric deformation between the residual deformation of foundation and the subgrade-track structure, the model of the FST was built. The design speed of a double-track high-speed railway was $350 \mathrm{~km} / \mathrm{h}$, and the high-speed railway was nearly a straight line. The 3D model of the track-fastener-sleeper-slab-subgrade-foundation is shown in Fig. 3. The length of the model along the longitudinal line was $450.0 \mathrm{~m}$, the maximum width of the foundation was $120.0 \mathrm{~m}$, and the total height was $107.8 \mathrm{~m}$. The 
subgrade was a trapezoidal structure with a height of $7.0 \mathrm{~m}$, a top width of $13.6 \mathrm{~m}$, and a bottom width of $34.3 \mathrm{~m}$. The longitudinal distance between the adjacent sleepers along the line was $0.625 \mathrm{~m}$.

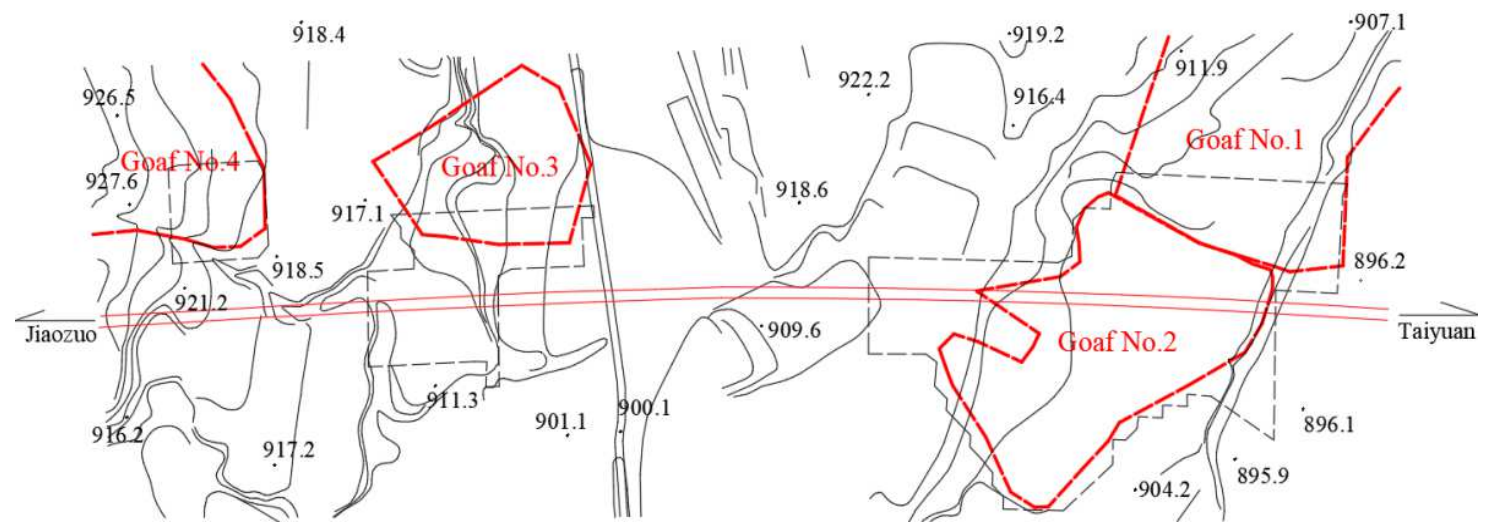

Fig. 2. The high-speed railway and the mined-out areas

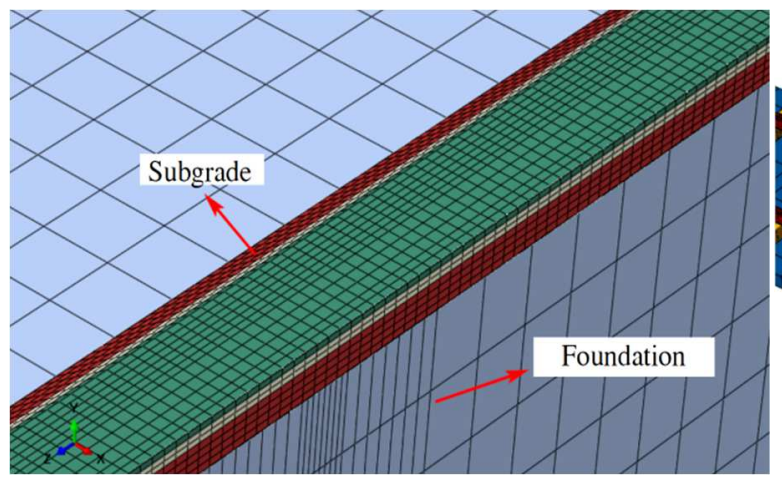

(a) Subgrade-foundation interaction

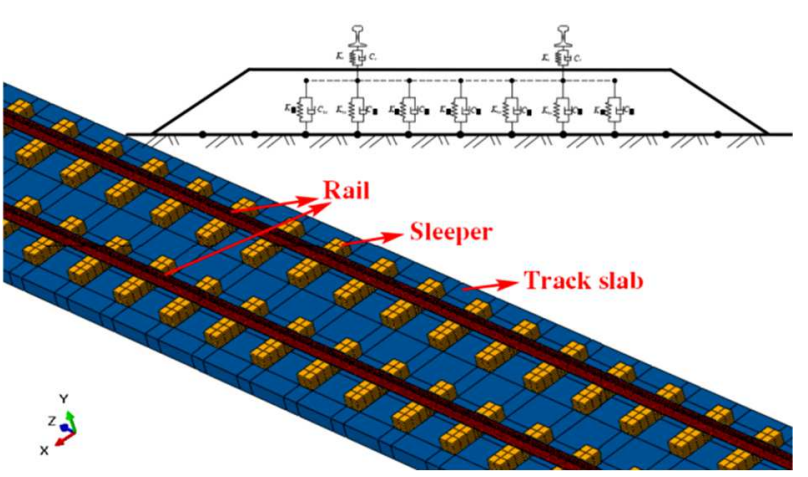

(b) Track-structure

Fig. 3. 3D model of the foundation-subgrade-track above the mined-out areas

The investigation of geotechnical engineering was properly generalized, and the soil layer of the site was 4 layers. The main parameters of the subgrade and foundation obtained from the laboratory tests are shown in Tab. 1. Based on the relevant provisions of the standard of High-Speed Railway Design Code in China (TB 106212009), the Mohr-Coulomb constitutive model was adopted for the top layer of the bed, bottom layer of the bed, and foundation.

Tab. 1. Parameters of subgrade and foundation (Szurgott et al., 2020)

\begin{tabular}{cccccccccc}
\hline Name & $\begin{array}{c}\rho \\
{\left[\mathrm{kg} / \mathrm{m}^{3}\right]}\end{array}$ & $\begin{array}{c}c \\
{[\mathrm{kPa}]}\end{array}$ & $\begin{array}{c}\varphi \\
{\left[{ }^{\circ}\right]}\end{array}$ & $\begin{array}{c}E \\
{[\mathrm{MPa}]}\end{array}$ & $v$ & $\zeta$ & \multicolumn{2}{c}{$\begin{array}{c}\text { Rayleigh damping } \\
\text { coefficient }\end{array}$} \\
\hline Fill & 1800 & 20 & 19 & 10 & 0.30 & 0.078 & 0.2630 & 0.0244 \\
New loess & 1860 & 32 & 21 & 18 & 0.25 & 0.065 & 0.2129 & 0.0199 \\
Old loess & 1920 & 36 & 22 & 21 & 0.25 & 0.053 & 0.1382 & 0.0141 \\
Mudstone & 2200 & 156 & 25 & 48 & 0.19 & 0.036 & 0.1097 & 0.0091 \\
Top layer of the bed & 1950 & 32 & 28 & 380 & 0.30 & 0.080 & 0.2620 & 0.0244 \\
Bottom layer of the bed & 1900 & 26 & 25 & 200 & 0.30 & 0.070 & 0.2293 & 0.0214 \\
Foundation & 1860 & 25 & 22 & 160 & 0.20 & 0.107 & 0.2742 & 0.0304 \\
\hline
\end{tabular}

The physical modeling of the track structure was based on the following assumptions: the track axis was straight in the unloaded state, and the irregularities of the track surface were omitted. The deformed beam elements in bending and shearing were used for track modeling. A massless one-dimension vertically oriented spring and damper were used to simulate the fastening system. The spring was defined by a piecewise linear elastic relationship between force and displacement, while the damper had a constant damping coefficient. The subgrade and foundation were modeled with the eight-node solid elements. The sleeper was modeled as a rigid beam with appropriate constraints to enable it to move vertically. The ballast layer was modeled as a set of vertical nonlinear 
springs and dampers (Fig. 3b), with 7 pairs of these units under each sleeper. Finally, the ballast was distributed by the mass elements to nodes located in the track slab and the topsoil layer. The geometric and mechanical parameters of the track structure were listed in Tab. 2.

Tab. 2. Parameters of the track structure (Szurgott et al., 2020)

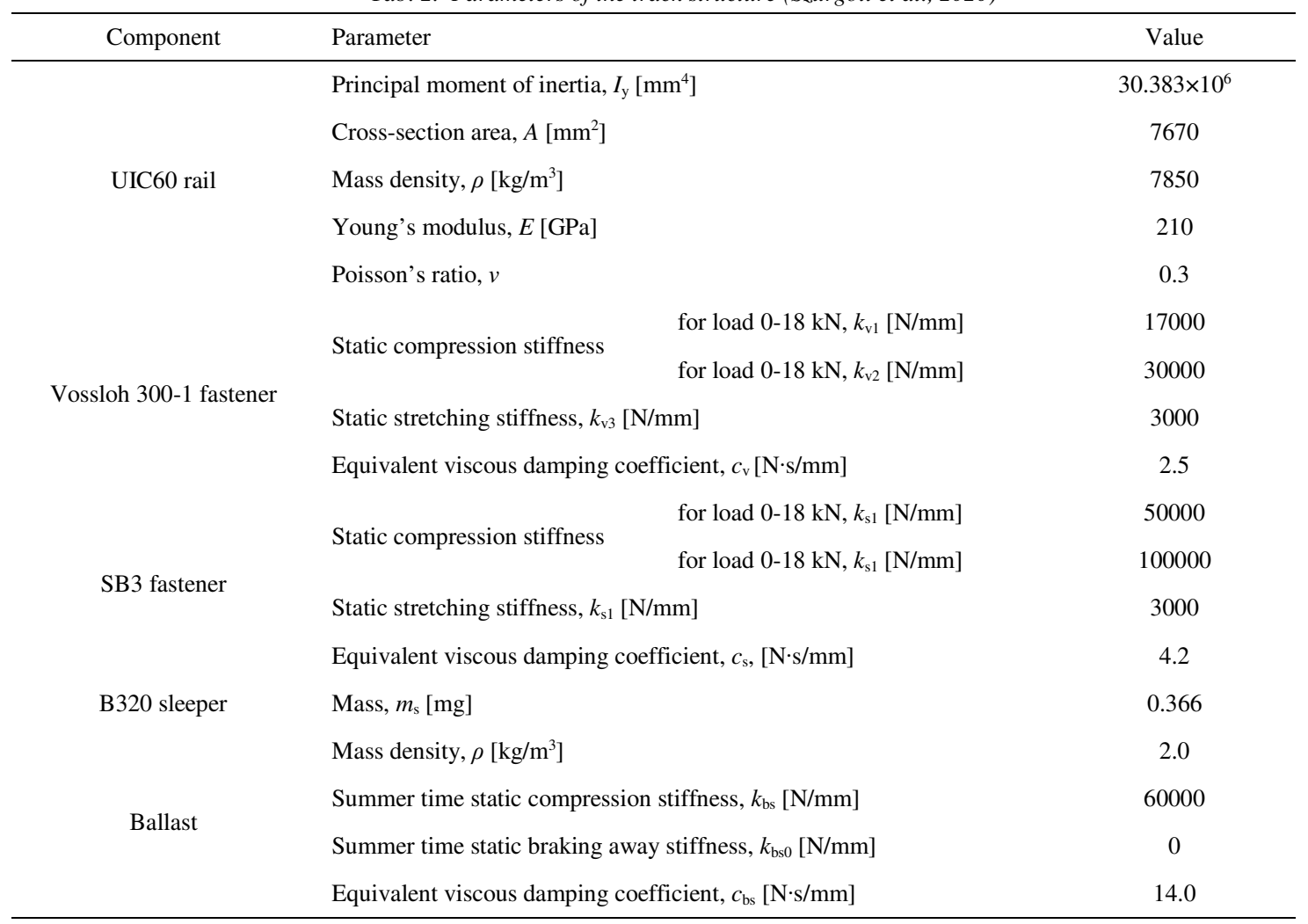

Since the contact pressure distribution on the wheel-rail contact spots was quite complicated and very uneven, which would bring severe challenges to the calculation convergence. To meet the needs of dynamic calculation stability, the grids of rails and sleepers needed to be small enough. In this study, the grid sizes of rails and sleepers were 0.05 and $0.06 \mathrm{~m}$, respectively. The number of nodes in the entire model was 553466, the number of elements was 366940, and the number of degrees of freedom was 1622598.

Loads and Boundary Conditions. To realize the movement of the load in the calculation process, the load moving band was first set along the direction of the movement of the load. The width of the moving band along the transverse track was the same as the width of the applied uniform load, and the length of the moving band along the longitudinal rail was the distance the wheel load travels.

The numerical method L-AMN proposed by Mezeh et al. (2021) was adopted to model the moving train load. The rail with length $l$ on the load path is divided into $n$ elements, where $\Delta t$ represents the time required to pass through each unit at a constant speed $v$ :

$$
\Delta t=\frac{1}{n v}
$$

At time $t$, the moving load is considered to be acting on the left node $I$ (the load moved from left to right). It remains in the same position until the first temporary node in time $t+\Delta t$ is imported into the grid in order to determine the loading direction. Before deleting, the next temporary node is created, and so on. This process of adaptive meshing in a fixed reference system gives rise to the concept of Mobile Node. It should be noted that the Hermite interpolation polynomial is used to initialize the position of the $j^{\text {th }}$ temporary node at the end of each calculation step, i.e., the time of $t+j \cdot \Delta t$, such as at $1 \leq j \leq S_{\mathrm{x}}-1$, to ensure the compatibility of the deflection and slope of adjacent units. Therefore, the cubic polynomial representing the vertical displacement field $u$ and plane rotation field $e$ in the loaded finite element local reference system $x$ is:

$$
\begin{aligned}
& u\left(x_{l}\right)=N_{1} u_{h}+N_{2} \theta_{h}+N_{3} u_{i+1}+N_{4} \theta_{i+1} \\
& \theta\left(x_{l}\right)=N_{1}^{\prime} u_{h}+N_{2}^{\prime} \theta_{h}+N_{3}^{\prime} u_{i+1}+N_{4}^{\prime} \theta_{i+1}
\end{aligned}
$$

The index $h$ in the preceding formula is the left node of the temporary finite element, and the results are as follows: 


$$
h=\left\{\begin{array}{cc}
i & j=1 \\
j-1 & \text { otherwise }
\end{array}\right.
$$

On the other hand, $N_{k}(1 \leq K \leq 4)$ is a form function and is expressed as follows by dimensionless variable $r$ :

$$
\left\{\begin{array}{cl}
N_{1}=1-3 r^{2}+2 r^{3}, & N_{2}=\left(r-2 r^{2}+r^{3}\right) l_{\mathrm{e}} \\
N_{3}=3 r^{2}-2 r^{3}, & N_{4}=\left(-r^{2}+r^{3}\right) l_{\mathrm{e}}
\end{array}\right.
$$

where, $R$ is the relative distance of temporary nodes, $r=x_{l} / l_{e}$.

Finally, let $x_{l}=v_{t}$, the vertical displacement $u_{j}$, and surface rotation of the temporary node $\theta_{j}$ can be determined by Eq. (5). At the end of the calculation, according to the equilibrium state of the system, the initial linear velocity $u$ is obtained by using a similar equation ' $i_{j}$ and angular velocity $\dot{\theta}_{j}$ :

$$
\begin{aligned}
& \dot{u}_{j}=N_{1} \dot{u}_{h}+N_{2} \dot{\theta}_{h}+N_{3} \dot{u}_{i+1}+N_{4} \dot{\theta}_{i+1} \\
& \dot{\theta}_{j}=N_{1}^{\prime} \dot{u}_{h}+N_{2}^{\prime} \dot{\theta}_{h}+N_{3}^{\prime} \dot{u}_{i+1}+N_{4}^{\prime} \dot{\theta}_{i+1}
\end{aligned}
$$

In addition, the process can be generalized by creating multiple mobile nodes to model multiple moving loads. In the dynamic analysis of geoengineering, selecting boundary condition plays an important role in the accuracy and credibility of the results. Additionally, radiation damping is the key to the soil-structure dynamic analysis to simulate the infinite foundation. To eliminate the influence of the static boundaries on the reflection of stress waves, the infinite element CIN3D8 is used to simulate the infinite element boundary, which can effectively simulate the radiation damping and elastic recovery performance of the foundation (Xue, 2017; Yang et al., 2019).

Simulation of Foundation Settlement. The causes of the uneven foundation settlement are complex and diverse. Theoretically speaking, uneven settlement can be roughly divided into two types: the mutation type and the delayed type. The settlement deformation caused by the subsidence of the mined-out areas can be classified as the delayed type. The residual deformation of the foundation under the high-speed railway and the accumulated deformation under the upper vibration load will lead to the damage of the track structure, which will affect the operation safety of the high-speed railway. The spatial position relationship between the foundation and the subgrade of the high-speed railway is shown in Fig. 4.

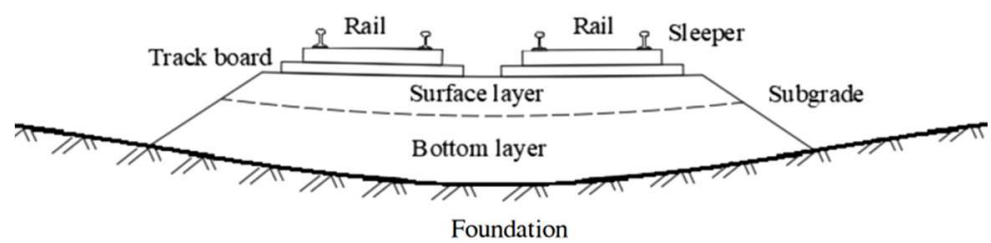

Fig. 4. Spatial position between foundation and subgrade of the high-speed railway

To study the influence of the foundation settlement on the train operation and the mechanical properties of the track structure, the half-wave sine curve is usually used in Japan, while the concave full-wave cosine curve is widely used in China (Guo et al., 2018), and its description function is as follows:

$$
f(x)=\frac{A}{2}\left(1+\cos f_{0}\left(\frac{2 \pi x}{l}\right)\right)
$$

where, $x$ is the coordinate of a certain point along the longitudinal direction of the line. $A$ is the settlement amplitude, and $l$ is the settlement wavelength.

In the 3D model of the subsidence area of the foundation, the Eq. (8) can be rotated one week along the $z$ axis to obtain a 3D settlement surface, as shown in Fig. 5, the description function is:

$$
f(x, y)=\frac{A}{2}\left(1+\cos f_{0}\left(\frac{2 \pi}{l} \sqrt{x^{2}+y^{2}}\right)\right)
$$

where, $x$ and $y$ are the plane coordinates of a point in the settlement area.

The subsidence surface in Fig. 5 is taken as the uneven subsidence area of the foundation in the mined-out areas under the high-speed railway. The simulations were carried out for subsidence amplitude is $0.2 \mathrm{~m}$, and the wavelength between 10 and $60 \mathrm{~m}$ in increments of $10 \mathrm{~m}$. 


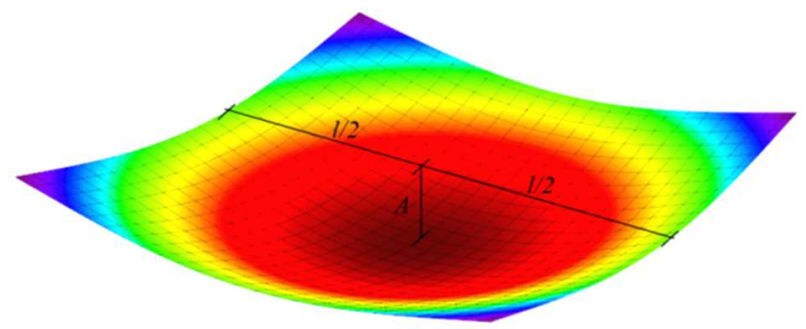

Fig. 5. Concave full-wave cosine surface

Simulation of Interlayer Contact. Many scholars usually used the simple tie link to deal with the interlayer contact (Xue, 2017; Wang et al., 2019; Yi et al., 2019). However, this kind of connection is only suitable for the case of a tight connection between the layers, but not applicable to the case of a large difference in material stiffness and not very tight constraint between the layers.

It is particularly important to set the connection mode between the layers of the ballastless track. Considering that the connection between the layers of ballastless track concrete is tight and the relative sliding is very small under the static state, the friction of the solid contact surface can be ignored. The tie connection mode of the software can not only ensure the deformation coordination between the adjacent surfaces but also choose not to restrict the rotational freedom of the corresponding nodes on the two surfaces, which is closer to reality than the common nodes. However, the connection between the ballastless track support layer/base plate and the subgrade surface is not very tight, and the phenomenon of separation, slippage, and voiding may occur under the action of uneven settlement. Therefore, the contact between the two surfaces is set: the normal contact is the "hard contact" in ABAQUS; that is, the two surfaces can only transmit normal force in the compressed state, which limits the possible penetration phenomenon in the calculation. The tangential contact uses coulomb friction combined with the "elastic slip deformation" introduced in the software to facilitate numerical calculations. The specific contact characteristics are shown in Fig. 6 . The above settings can better simulate the connection state between the various layers of the ballastless track, thereby accurately reflecting the situation that the uneven settlement of the foundation is transmitted upwards to the subgrade-track structure.

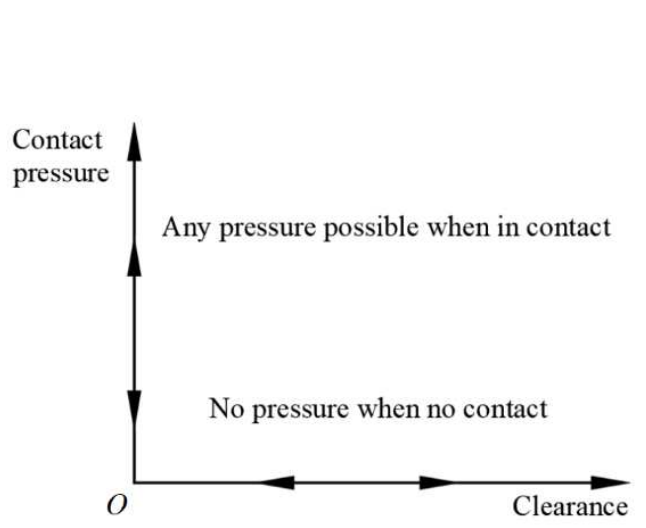

(a) Normal contact

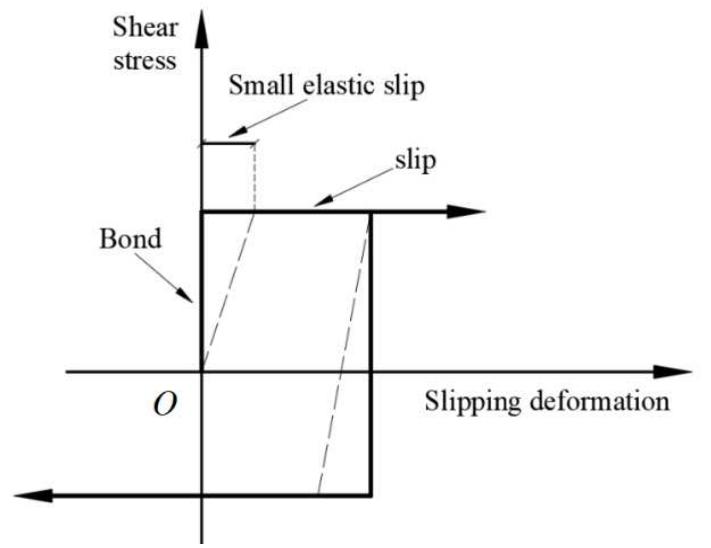

(b) Tangential contact

Fig. 6. Contact characteristics between subgrade and support layer.

Fig. 7 shows that under the effect of the uneven settlement of the subgrade, the deformation of the steel rail, the track slab, and the supporting layer is basically consistent due to the higher integrity. However, the contact behavior between the bearing layer and subgrade may be significantly different. The surface-to-surface contact method can accurately reflect the possible voids and disengage phenomenon between the track and the subgrade so as to get closer to the actual track deformation characteristics.

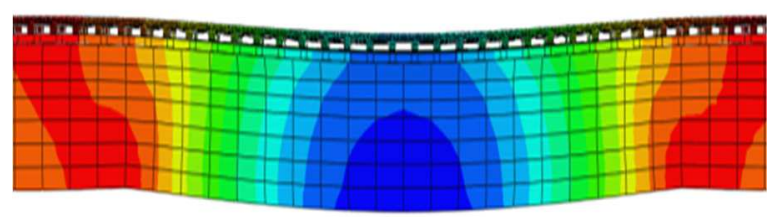

(a) Tie links [no separation]

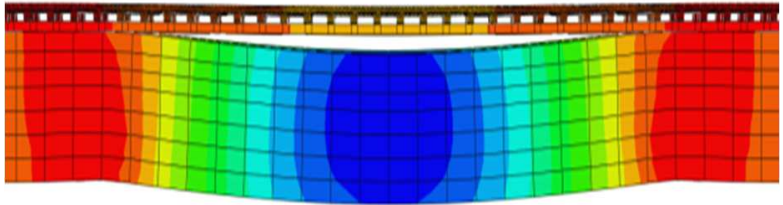

(b) Surface to surface contact [separation]

Fig. 7. Track structure deformation caused by differential settlements of subgrade. 


\section{Results and Discussion}

\section{Influence of Differential Settlement of Foundation on Deformation of Track-structure}

The uneven settlement amplitude of the foundation is set as $0.2 \mathrm{~m}$; the settlement wavelength is increased from 10 to $60 \mathrm{~m}$ at equal intervals. The longitudinal variation curve of the rail deformation is shown in Fig. 8a. When the amplitude of the uneven settlement of the subgrade is constant, the smaller the settlement wavelength is, the weaker the settlement deformation of rail is, and the greater the difference with the subgrade deformation is, which means that the larger the empty lifting gap is between the track support layer and the subgrade surface layer, the more significant the impact on the track structure stress and train operation. As shown in Fig. 8b, when the uneven settlement wavelength of the subgrade is within $30 \mathrm{~m}$, the track deformation increases linearly. After exceeding $30 \mathrm{~m}$, the following deformation of the railway gradually tends to be stable, the gap between the track structure and subgrade gradually shrinks, and the deformation amplitude and subgrade settlement reduction finally reach the same value and no longer change with the settlement wavelength of the foundation. The variation law of the railway with the settlement wavelength can be expressed by the following formula:

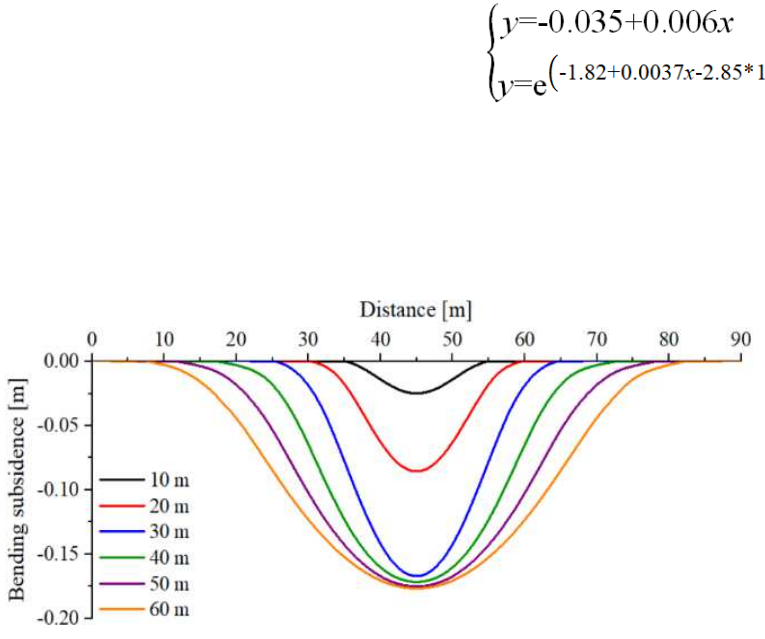

(a) Deflection of track-structure

$$
\begin{aligned}
& x<30 \\
& x \geq 30
\end{aligned}
$$

Fig. 8. Deformation characteristics of track-structure with different settlement wavelengths

The uneven settlement wavelength of the foundation is set as $30 \mathrm{~m}$, and the settlement amplitude increases from 0.25 to $1.50 \mathrm{~m}$ at equal intervals. The longitudinal variation curve of the railway deformation is shown in Fig. 9a. Under the action of the different amplitude of cosine type settlement, the deformation form of the railway is cosine type, and the deformation range of the railway has different degrees of diffusion compared with the uneven settlement range of the foundation. With the increase of the subsidence amplitude, the railway in the settlement edge area appears local up-arching phenomenon. This is because the elevation difference between the inner and outer edges of the settlement area increases due to the increase of the settlement amplitude, leading to the slight upward arching of the railway at the outer edge of the settlement. When the settlement amplitude is less than $1.0 \mathrm{~m}$, there is no obvious upward arching at the settlement edge, and when the settlement amplitude is greater than $1.25 \mathrm{~m}$, the railway's arching height and maximum deformation tend to be stable gradually.

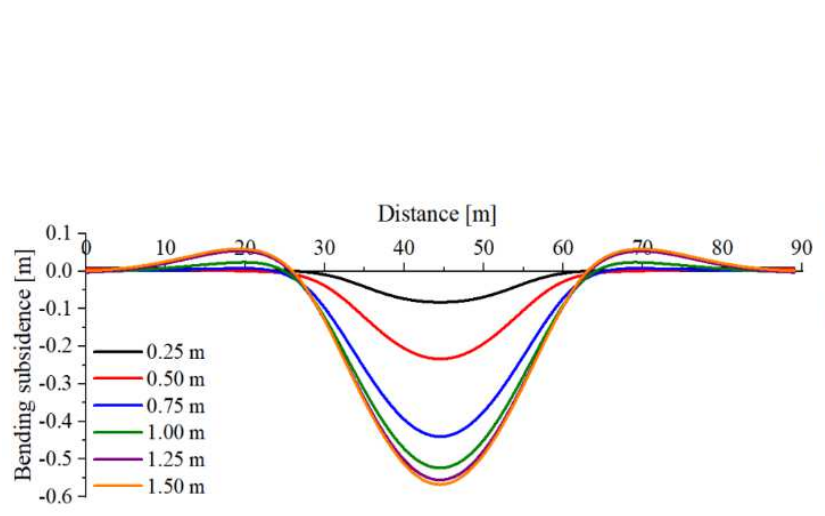

(a) Deflection of track-structure

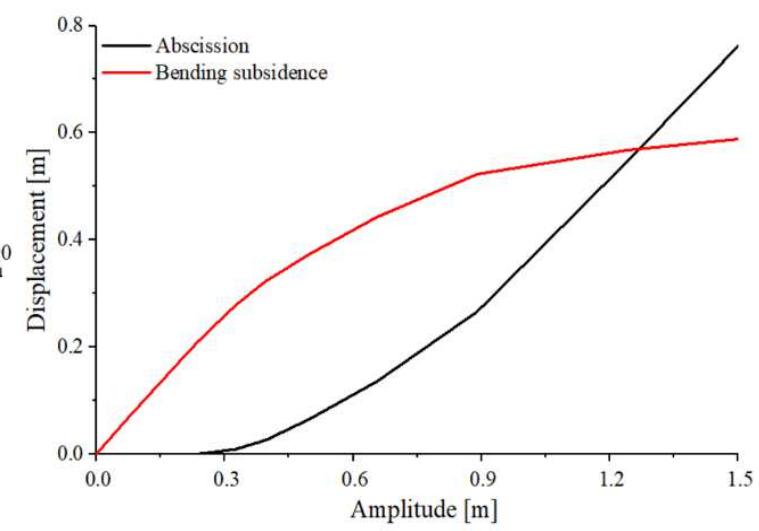

(b) Track-structure deformation and abscission

Fig. 9. Deformation characteristics of track-structure with different settlements of the foundation 
As can be seen from Fig. 9b, the deflection of the railway increases with the increase of the settlement amplitude of the foundation, and the increase tends to be gentle when the settlement amplitude exceeds $0.9 \mathrm{~m}$. In addition, it can be seen that when the settlement amplitude is less than $0.3 \mathrm{~m}$, there is no separation between the track structure and the subgrade. When the settlement amplitude is more than $0.3 \mathrm{~m}$, there is a separation between these two ones. After $0.9 \mathrm{~m}$, the amount of clearance increases sharply. The variation law of the railway with settlement amplitude can be expressed by the following formula:

$$
y=0.67\left(1-\mathrm{e}^{-1.58 x}\right)
$$

\section{Spatiotemporal Effect Analysis of Track-structure Deformation}

Taking the settlement amplitude of $0.2 \mathrm{~m}$ as an example, the temporal and spatial evolution mechanism of the track-structure deformation with foundation settlement under different wavelengths is shown in Fig. 10. The uneven settlement of the foundation is simulated in $0-1 \mathrm{~s}$, and the dynamic response of the track structure is directly above the settlement center under a 1-2s train dynamic load.

It can be seen from Fig. 10, under the action of the uneven settlement of the foundation at different wavelengths, the subgrade and track-structure in the settlement area subside downward with the increase of foundation settlement. At the initial stage of the foundation settlement, the deformation of the subgrade and trackstructure appears a short lag because the track structure does not reach the yield strength and then continues to sink with the foundation settlement. When the settlement wavelength is less than $30 \mathrm{~m}$, the deformation degree of the track-structure is far less than that of the subgrade, and the deformation degree of the subgrade surface is less than that of the foundation. All three show low following, which will eventually cause separation between the track structure and the subgrade. When the settlement wavelength is greater than $30 \mathrm{~m}$, the deformation difference among the track structure, subgrade, and foundation is very small, showing a high following. In addition, when the track structure and the subgrade show the low following, that is, there is a separation phenomenon between these two ones, and the vibration of the track structure is more intense under the train vibration load. In contrast, when there is no separation between the track structure and the subgrade, the vibration of the track structure is less severe.

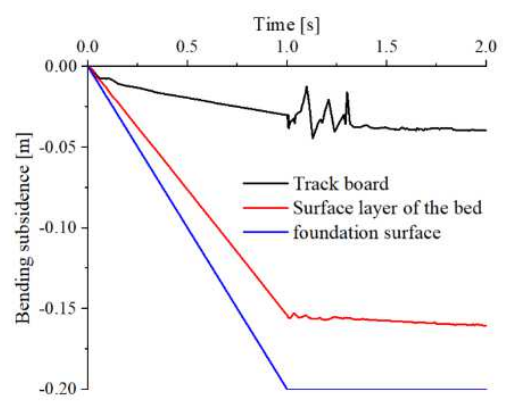

(a) $10 \mathrm{~m}$

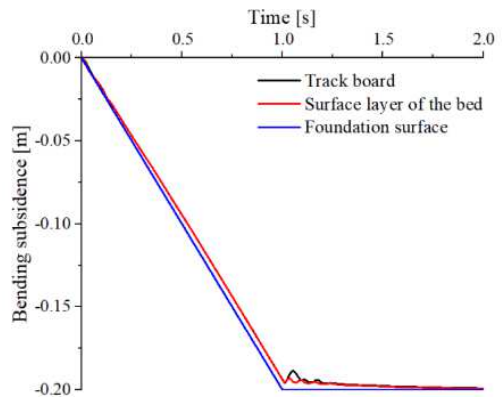

(d) $40 \mathrm{~m}$

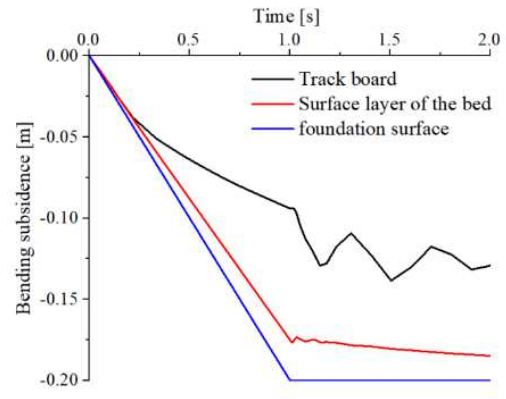

(b) $20 \mathrm{~m}$

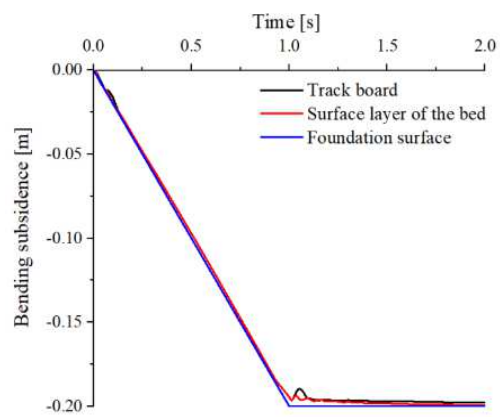

(e) $50 \mathrm{~m}$

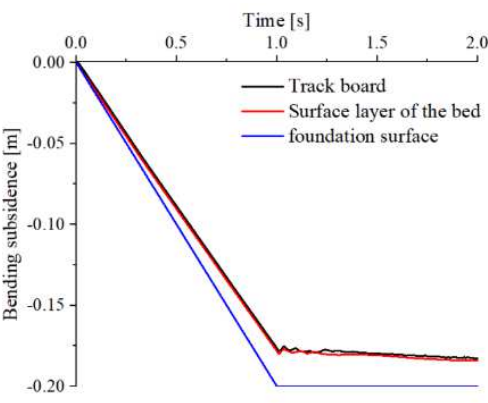

(c) $30 \mathrm{~m}$

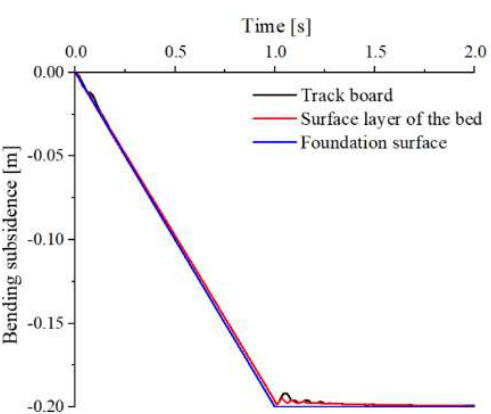

(f) $60 \mathrm{~m}$

Fig. 10. Deformation of subgrade and track-structure with differential settlements of the foundation

\section{Influence of Differential Settlement on Separation between Subgrade and Track-structure}

Compared with the subgrade, the rigidity of the track structure is larger, and the bottom surface of the track plate and the subgrade surface are not closely linked and fixed. Therefore, when the settlement wavelength is small and the amplitude is large, there will be an obvious separation phenomenon between the track plate and the subgrade. It can be seen from the previous section that the separation phenomenon includes the upper arch of the track-structure located at the positive curvature of the settlement curve, and the hanging locates at the negative curvature. 
At this time, the passing of a high-speed train will not only affect the safety of the train, but also the deformation and vibration of the track structure in the separation section are more severe than those in the close contact section, as shown in Fig. 11. Therefore, it is very important to study the following deformation law of the track structure and subgrade for the safe operation of the high-speed railway and the fatigue life of the track structure.

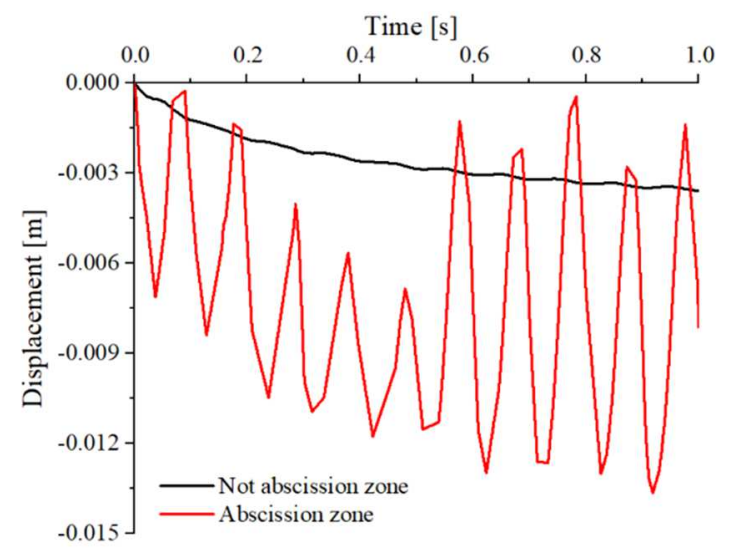

Fig. 11. The dynamic response of the track structure under the vibration load of the train

Taking the settlement wavelength of $40 \mathrm{~m}$ as an example, the track-structure deformation and following property under different settlement amplitudes are shown in Fig. 12. The track structure and subgrade follow well when the settlement amplitude is small. With the increase of the settlement amplitude, first of all, in the peripheral area of the settlement center, the separation phenomenon between the track structure and subgrade gradually appears. As the settlement amplitude continues to increase, the separation range gradually diffuses to the settlement center and finally becomes void. In addition, the track structure is slightly arched at the settlement edge.

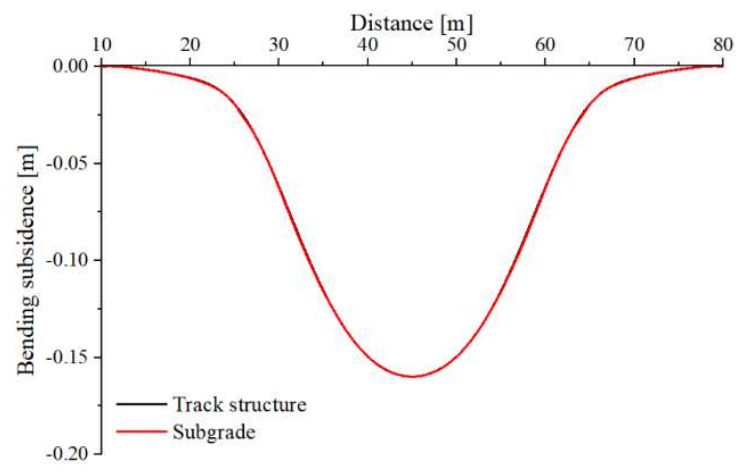

(a) $0.2 \mathrm{~m}$

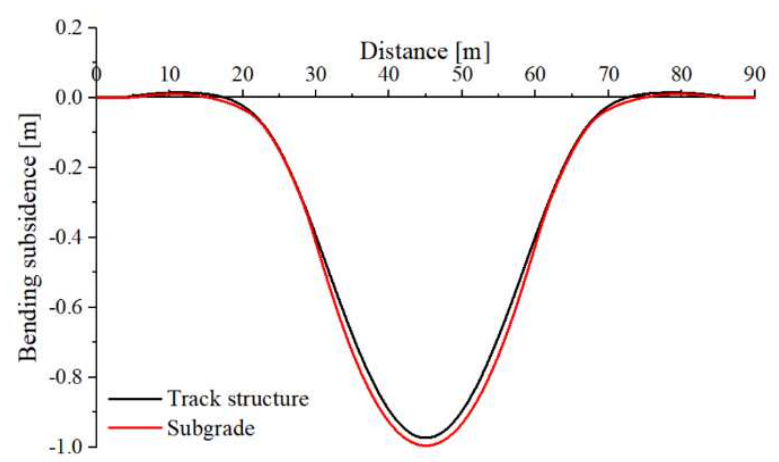

(c) $1.0 \mathrm{~m}$

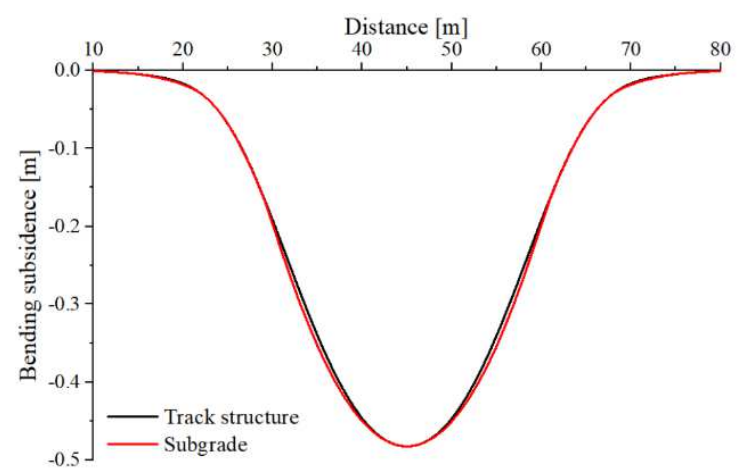

(b) $0.5 \mathrm{~m}$

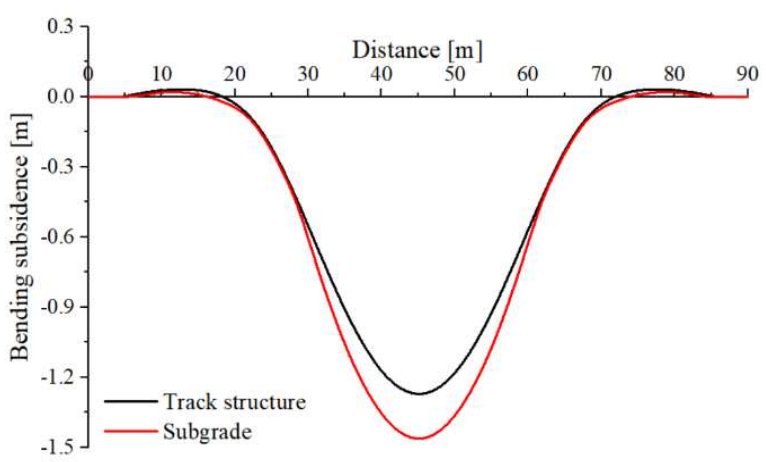

(d) $1.5 \mathrm{~m}$

Fig. 12. The following of track-structure under different settlement amplitudes

Taking the settlement amplitude of $0.5 \mathrm{~m}$ as an example, the track-structure deformation and following property under different settlement wavelengths are shown in Fig. 13. It can be seen from Fig. 13 that the variation law of the track-structure deformation and subgrade following property under different settlement wavelengths are 
just opposite to the variation law of the track-structure deformation and subgrade following property under different settlement amplitudes. When the settlement wavelength is small, the track structure and subgrade have a poor following, resulting in the void phenomenon. With the increase of settlement wavelength, the void area gradually shrinks and finally keeps consistent with the subgrade deformation.

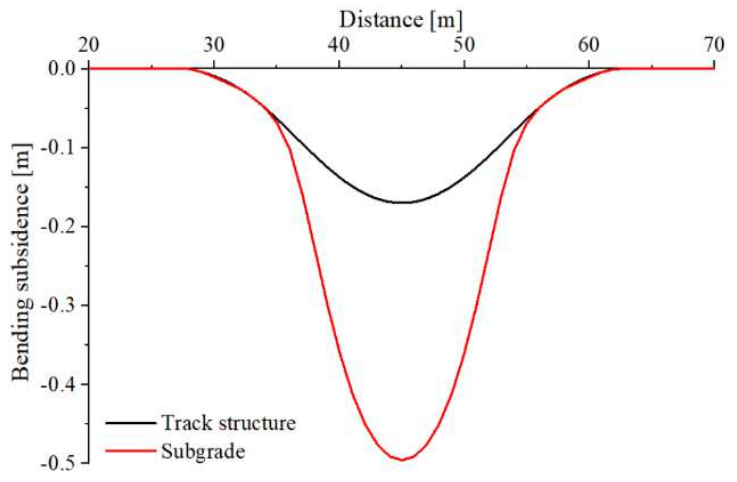

(a) $20 \mathrm{~m}$

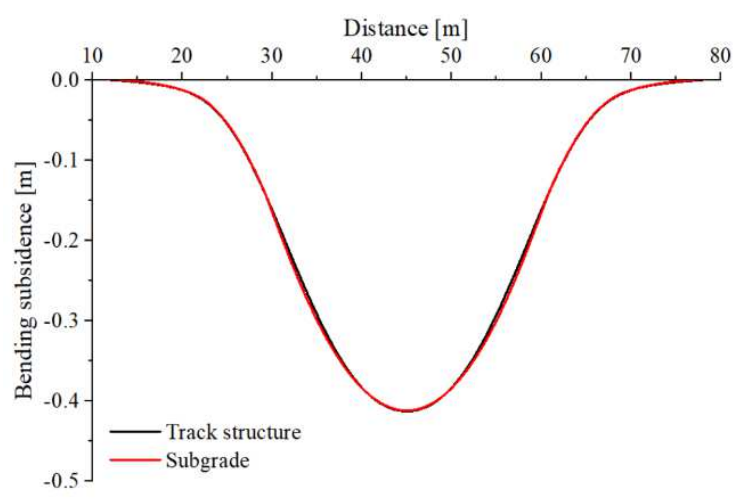

(c) $40 \mathrm{~m}$

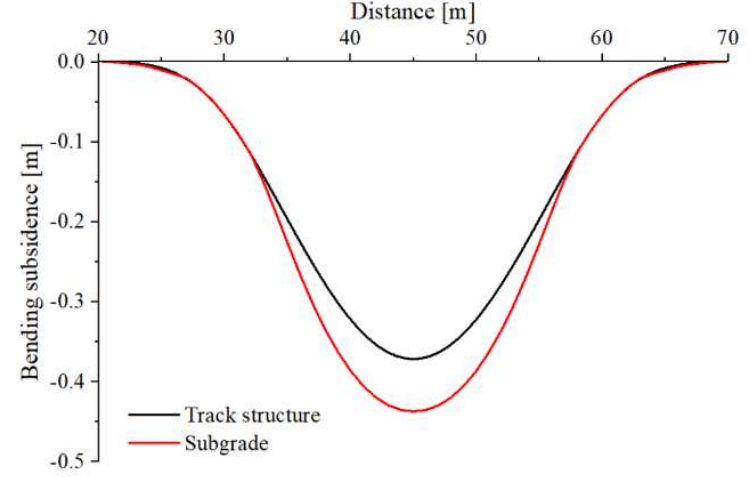

(b) $30 \mathrm{~m}$

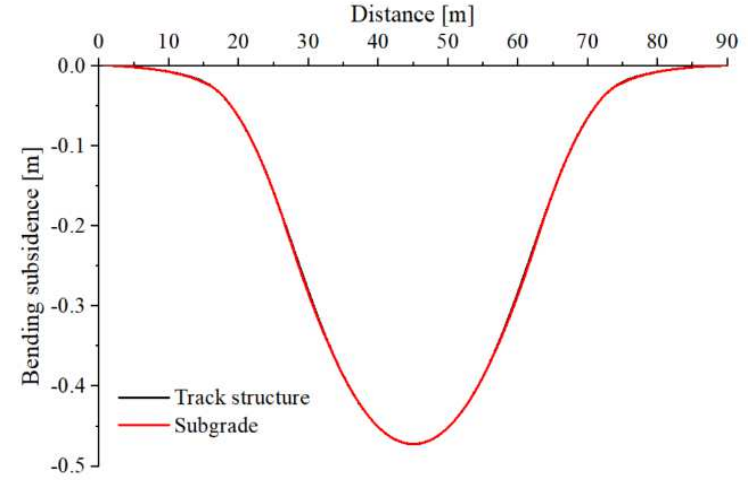

(d) $50 \mathrm{~m}$

Fig. 13. The following changes of track structure under different settlement wavelengths

The separation and voids between the track structure and the subgrade are the results of the combined action of the amplitude and wavelength of the settlement surface, and the curvature of the surface is determined by the wavelength and amplitude. It can be seen from Eq. (8) that the settlement curve is a periodic cosine function, so the positive and negative curvature of the curve is the same, as shown in Fig. 14. To more intuitively reflect the relationship between the separation of the track structure and subgrade and the settlement wavelength and amplitude, the curve's curvature is introduced to characterize the wavelength and amplitude of the settlement curve comprehensively. Assuming that the second derivative of the settlement curve function $f(x)$ at the point $x_{0}$ is $f^{\prime \prime}$ $\left(x_{0}\right)$, and $f^{\prime \prime}\left(x_{0}\right) \neq 0$, then there is an osculation circle at this point, whose radius is:

$$
r=\frac{\left(1+\left(f\left(x_{0}\right)\right)^{2}\right)^{\frac{3}{2}}}{\left|f^{\prime}\left(x_{0}\right)\right|}
$$

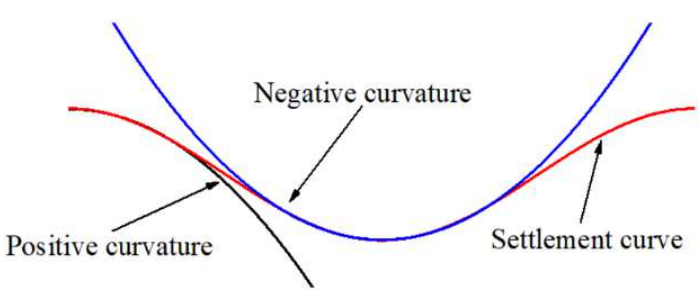

Fig. 14. The curvature of the settlement curve

In this case, the curvature of the curve, that is, the curvature of the osculation circle is: 


$$
K=\frac{1}{r}=\frac{\left|f^{\prime \prime}\left(x_{0}\right)\right|}{\left(1+\left(f\left(x_{0}\right)\right)^{2}\right)^{\frac{3}{2}}}
$$

where, $r$ is the radius of curvature and $K$ is the curvature.

The curvature radius of different settlement surfaces can be obtained from Eq. (12), as shown in Tab. 3. The larger the wavelength of the settlement surface is, the smaller the amplitude is, and the larger the curvature radius is, that is, the smaller the curvature is. According to the numerical results and the data in Tab. 3, the internal relationship of the separation amount between the track structure and the subgrade, and the curvature radius of the settlement surface are shown in Fig. 15. As seen from Fig. 15, the separation amount between the track structure and subgrade decreases sharply with the increase of curvature radius. When $r>200 \mathrm{~m}$, the separation amount gradually tends to 0 , and the following between them is good. By fitting the data, it is found that the relationship of the separation amount of the track-structure and the curvature radius satisfies the exponential distribution:

$$
y=\mathrm{e}^{(-0.76-0.02 r)}
$$

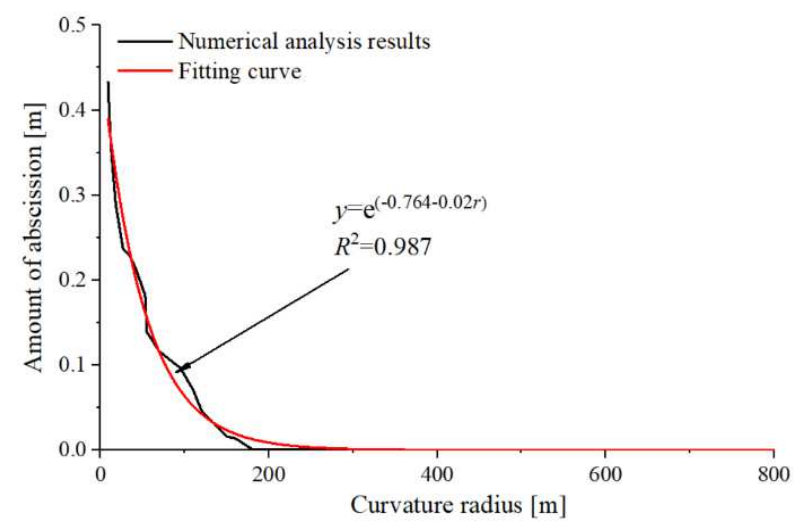

Fig. 15. Separation amount with a curvature radius of the settlement

\begin{tabular}{|c|c|c|c|c|c|c|}
\hline \multirow{2}{*}{ Amplitude [m] } & \multicolumn{6}{|c|}{ Wavelength [m] } \\
\hline & 10 & 20 & 30 & 40 & 50 & 60 \\
\hline 0.1 & 55 & 220 & 500 & 900 & 1350 & 2000 \\
\hline 0.2 & 27 & 110 & 250 & 400 & 700 & 1000 \\
\hline 0.3 & 18 & 70 & 160 & 300 & 450 & 650 \\
\hline 0.4 & 13 & 53 & 120 & 220 & 340 & 480 \\
\hline 0.5 & 11 & 42 & 95 & 180 & 280 & 390 \\
\hline 0.6 & 9 & 35 & 79 & 150 & 230 & 320 \\
\hline
\end{tabular}

Tab. 3. The curvature radius of different settlement surfaces [m]

In this study, the model of the foundation settlement above the mined-out areas under the action of the highspeed railway was analyzed, and the deformation and dynamic response characteristics of the track structure and subgrade of the high-speed railway above the mined-out areas were revealed. In the previous studies, most scholars had mainly conducted in-depth analysis on the deformation of the track, subgrade, bridge, and other structures from the aspects of the train weight, running speed, and dynamic load, but did not involve the content of the foundation above the mined-out areas (Salcher et al., 2015; Wang et al., 2019). Furthermore, they did not distinguish the contact categories between the track structure and subgrade with large differences in material stiffness, which would affect the accuracy of the research results (Yang et al., 2019; Xue et al., 2017). This study takes into account the abscission contact among these different structural attributes, which is more adaptive to the engineering practice. The influence law of the foundation settlement on the amount of the separation between the track-structure and subgrade is summarized through the method of mathematical statistics, which can provide a theoretical basis for the design of the track-structure and subgrade of the high-speed railway above the mined-out areas. 


\section{Conclusions}

To reveal the deformation and dynamic response characteristics of the track-structure and subgrade of the high-speed railway above the mined-out areas, the finite element model of the non-uniform settlement of the foundation under high-speed railway was proposed, and the deformation and dynamic response characteristics of the track-structure under different foundation settlement range were analyzed by taking six kinds of foundations with different settlement range as examples. The coupling effect of geometric deformation between the track structure and subgrade of the high-speed railway was summarized by combining theoretical analysis and numerical simulation. The main conclusions are obtained as follows:

(1) The application possibility of ABAQUS/CAE in modeling and simulation of the uneven settlement of the foundation and transient vibration of the track-structure of the high-speed railway is introduced. The interlayer contact and the displacement boundary of the non-uniform settlement are considered, which is more in line with the engineering practice and allows the finite element model of the foundation under the high-speed railway to be developed in a relatively short time.

(2) The cosine-type uneven settlement of the foundation will cause "cosine-like" deformation of the track structure when it propagates upwards. The wavelength, wave depth, and upward arch amplitude of the railway deformation curve are comprehensively controlled by the wavelength and amplitude of the foundation settlement. In addition, when the wavelength is more than $30 \mathrm{~m}$, and the amplitude is less than $0.9 \mathrm{~m}$, the deformation of the track structure has a high following with that of the subgrade.

(3) The curvature of the settlement curve is introduced to comprehensively represent the internal relationship between the separation deformation of the track structure and the settlement wavelength and amplitude of the foundation. The separation amount and curvature radius satisfy the exponential distribution characteristics, and the separation between the track structure and the subgrade is more prominent when the curvature radius is less than $200 \mathrm{~m}$. Otherwise, it is very weak.

The conclusions can provide a reference for the establishment of the model and safety assessment of the highspeed railway above the mined-out areas. However, since there are some assumptions in this study, such as the contact pressure of the wheel-rail contact spot being assumed to be uniformly distributed and the ideal elasticplastic model being adopted to the subgrade. Besides, the influence of the relative position between the mined-out areas and the high-speed railway line is not considered in detail. So these factors, as mentioned earlier, are needed to be considered in the next study.

\section{Reference}

Colaco, A., Costa, P.A., Castanheira-Pinto, A. Amado-Mendes, P. and Calçada, R. (2021). Experimental validation of a simplified soil-structure interaction approach for the prediction of vibrations in buildings due to railway traffic. Soil Dynamic and Earthquake Engineering, 141. pp. 106499. DOI: 10.1016/j.soildyn.2020.106499.

Bian, X.C., Duan, X., Li, W. and Jiang, J.Q. (2021). Track settlement restoration of ballastless high-speed railway using polyurethane grouting: Full-scale model testing. Transportation Geotechnics, 26. pp. 100381. DOI: 10.1016/j.trgeo.2020.100381.

Billenstein, D., Dinkel, C. and Rieg, F. (2018). Automated topological clustering of design proposals in structural optimisation. International Journal of Simulation Modelling, 17(4). pp. 657-666. DOI:10.2507/JSIMM17(4)454.

Guo, Y. and Zhai, W.M. (2018). Long-term prediction of track degradation in high-speed vehicle-ballastless track system due to differential subgrade settlement. Soil Dynamics and Earthquake Engineering, 113. pp. 1-11. DOI: 10.1016/j.soildyn.2018.05.024.

Guo, Y., Zhai, W.M. and Sun, Y. (2018). A mechanical model of vehicle-slab track coupled system with differential subgrade settlement. Structural Engineering and Mechanics, 66(1). pp. 15-25. DOI: 10.12989/sem.2018.66.1.015.

Huang, Q., Huang, H.W. and Ye, B. (2017). Dynamic response and long-term settlement of a metro tunnel in saturated clay due to moving train load. Soils and Foundations, 57(6). pp. 1059-1075. DOI: 10.1016/j.sandf.2017.08.031.

Krantovska, O., Petrov, M., Ksonshkevych, L., Orešković, M. Synii, S. and Ismailova, N. (2019). Numerical simulation of the stress-strain state of complex-reinforced elements. Technical Journal, 13(2). pp. 110-115. DOI: $10.31803 / \operatorname{tg}-20190417112619$.

Lee, I.I., Choi, Y.T., Lee, M. and Yune, C. Y. (2018). Investigation of influential factors on residual settlement of Korean high-speed railway on soft ground. KSCE Journal of Civil Engineering, 22. pp. 3312-3320. DOI: 10.1007/s12205-017-0472-6. 
Mezeh, R., Mroueh, H., Hosseingholian, M. and Sadek, M. (2021). Fully-coupled numerical model for ballasted track analysis-field measurements and predictions. Transportation Geotechnics, 27. pp. 100483. DOI: 10.1016/j.trgeo.2020.100483.

Mezeh, R., Sadek, M. and Hage, C. F. (2018). Adaptive meshing scheme for prediction of high-speed moving loads induced ground vibrations. Computer and Geotechnics, 100. pp. 188-202. DOI: 10.1016/j.compgeo.2018. 03.014.

Neves, S.G.M., Montenegro, P.A. and Jorge, P.F.M. (2021). Modelling and analysis of the dynamic response of a railway viaduct using an accurate and efficient algorithm. Engineering Structure, 226. pp. 111308. DOI:10.1016/j.engstruct.2020.111308.

Ntotsios, E. (2021). Ground vibrations from high-speed railways: prediction and mitigation. Journal of Sound and Vibration, 490. pp. 115563. DOI: 10.1016/j.jsv.2020.115563.

Peixer, M.A., Montenegro, P.A. and Carvalho, H. (2021). Running safety evaluation of a train moving over a highspeed railway viaduct under different track conditions. Engineering Failure Analysis, 121. pp. 1-17. DOI: 10.1016/j.engfailanal.2020.105133.

Ren, L.W., Ning, H., Zou, Y.F., Dun, Z.L., Guo, W.B. and Tian, Z.B. (2020). Research status and prospect on deformation control of high-speed railway subgrade in goaf site. Journal of China Coal Society, pp. 1-15. DOI: 10.13225/j.cnki.jccs.2020.0499.

Ren, L.W., Zhou, G.L., Dun, Z.L., He, T.Y., Yang, Q.W. and Zhang, M.X. (2018). Case study on suitability and settlement of foundation in goaf site. Rock and Soil Mechanics, 39(8). pp. 2922-2932. DOI: 10.16285/j.rsm.2018.0538.

Salcher, P. and Adam, C. (2015). Modeling of dynamic train-bridge interaction in high-speed railways. Acta Mechanica, 226(8). pp. 2473-2495. DOI:10.1007/s00707-015-1314-6.

Solonenko, I. (2019). The equipment for determining the impact of traffic environment on road pavement. Technical Journal, 13(2). pp. 149-153. DOI: 10.31803/tg-20190421134423.

Szurgott, P. and Bernacki, P. (2020). Modelling of steel-concrete bridge subgrade to a moving high-speed train. International Journal of Simulation Modelling, 19(1). pp. 29-40. DOI: 10.2507/IJSIMM19-1-499.

Wang, S.R., Li, N., Li, C.L., Zou, Z.S. and Chang, X. (2015). Instability mechanism analysis of pressure-arch in coal mining field under different seam dip angles. DYNA, 90(3). pp. 279-284. DOI: 10.6036/7530.

Wang, S.R., Shi, K.P., He, Y.S. and Wang, X.Q. (2019). Dynamic response analysis of middle pillar for ultrasmall spacing tunnels under train vibration loads. Journal of Engineering Science and Technology Review, 12(3). pp. 30-37. DOI: 10.25103/jestr.123.05.

Wang, S.R., Shi, K.P., Li, Z.H., Li, Z.C., and Wang, Y.F. (2019). Spatial distribution law of vibration acceleration of ultra-small-spacing tunnel under train moving loads. Journal of Engineering Science and Technology Review, 12(6). pp. 96-104. DOI: 10.25103/jestr.126.12.

Wang, S.R., Zhang, H.Q., Shen. N.Q. and Cao, H.Y. (2009). Analysis of deformation and stress characteristic of highway tunnels above mined-out regions. Chinese Journal of Rock Mechanics and Engineering, 28(6). pp. 1144-1151. DOI:10.3321/j.issn:1000-6915.2009.06.008.

Xue, F.C. (2017). Ture three-dimensional dynamic analysis of subway tunnel structure and surrounding soil under moving loads. Journal of the China Railway Society, 39(6). pp. 133-140. DOI: 10.3969/j.issn.10018360.2017.06.018.

Yang, W.B., Zou, T., Tu J.L.,Gu, X.X., Liu, X.C., Yan, Q.X. and He, C. (2019). Analysis of dynamic response of horseshoe cross-section tunnel under vibrating load induced by high-speed train. Rock and Soil Mechanics, 40(9). pp. 3635-3644. DOI: 10.16285j.rsm.2013.2286.

Yi, H., Qi, T., and Qian, W. (2019). Influence of long-term dynamic load induced by high-speed trains on the accumulative deformation of shallow buried tunnel linings. Tunnelling and Underground Space Technology, 84. pp. 166-176. DOI: 10.1016/j.tust.2018.11.005.

Yi, H.Y., Qi, T.Y., Qian, W.P., Lei, B., Pu, B.R., Yu, Y.Y., Liu, Y.X. and Li, Z. Y. (2019). Influence of long-term dynamic load induced by high-speed trains on the accumulative deformation of shallow buried tunnel linings. Tunnelling and Underground Space Technology, 84. pp. 166-176. DOI: 10.1016/j.tust.2018.11.005.

Zhang, C.L. and Jiang, G.L. (2020). Full-scale model testing of the dynamic response of lime-stabilized weathered red mudstone subgrade under railway excitation. Soil Dynamics and Earthquake Engineering, 130. pp. 111. DOI: $10.1016 /$ j.soildyn.2019.105999.

Zhang, Z.X., Zhang, Y.B., Zhao, Z.H. and Zhang, L.M. (2011). Experimental studyonthe stability analysisof goaf beneath tunnelunder traffic load. Journalof Taiyuan Universityof Technology, 42(5). pp. 534-538. DOI: 10.16355/j.cnki.issn1007-9432tyut.2011.05.022. 